\title{
Exploring the Factors Influencing e-Government use: Empirical Evidence from Zimbabwe
}

\author{
Willard Munyoka \\ Department of Business Information Systems, University of Venda, South Africa \\ willard.munyoka@univen.ac.za \\ DOI: 10.34190/EJISE.19.22.2.002
}

\begin{abstract}
The proliferation of e-government adoption in developing nations is anticipated to radically progress governance and transform government-to-citizen interactions and general administrative operations. More so, the benefits and level of e-government adoption in the public sector have been echoed world over; but remains subdued in the context of developing nations. This study investigates the effect of effort expectancy, price value, service quality, optimism bias and behavioural intention on citizens' decisions to use e-government systems in Zimbabwe. Informed by the extended Unified Theory of Acceptance and Use of Technology (UTAUT2) as a theoretical lens, a research model for this study was adapted and tested using quantitative data collected from a survey of 489 respondents in Zimbabwe. Using confirmatory factor analysis and structural equation modelling, the proposed model was validated, thus, the major contribution of this research. Findings of this study may be of value in policy formulation and restructuring by practitioners on e-government matters. Thus, the results shade a light to some of the key drivers and inhibitors of e-government adoption in developing nations. Despite achieving its aim, this study has its limitations which constitute the future research direction.
\end{abstract}

Keywords: E-government Systems, Use Behaviour, G2C, UTAUT2, Structural Equations Modelling, AMOS, Zimbabwe

\section{Introduction}

Electronic government (hereafter, e-government) refers to the use of information communication and technologies (henceforth, ICTs) by government agencies to facilitate wider access to government services, increase public accountability, reduce unnecessary bureaucracy and bottlenecks in governance, provide efficient and effective public services via online to citizens, businesses, other government agencies and employees (Palvia and Sharma, 2007). In the context of this study e-government systems refers to online government portals used by government agencies to offers public services to all its stakeholders (Bwalya, 2018). Online interactions between government agencies and its stakeholders can be classified into four broad models: government-to-citizen (G2C), government-to-business (G2B), government-to-government (G2G) and government-to-employees (G2E) (Kalamatianou and Malamateniou, 2017). Whilst most previous studies on these domains for developing nations looked at e-government readiness, developments and challenges (Nkohkwo and Islam, 2013), policy formulation, alignment and implementation (Mawela, Ochara and Twinomurinzi, 2017, Ruhode, 2016; Munyoka and Manzira, 2013) and adoption (Jain and Akakandelwa, 2014; Mutula and Olasina, 2014), Bwalya (2018) has articulated the need for more studies investigating the utilisation and impact of e-government on citizens in Africa.

The adoption of e-government systems by the public sector across many developing countries are well documented (United Nations, 2018; Verkijika and De Wet, 2018). More so, the potential of e-government to unlock new avenues of service provision and unearthing extraordinary solutions for the vast of socio-economic challenges confronting developing nations are undisputed (United Nations, 2018; Kyem, 2016). However, previous scholars (Verkijika and De Wet, 2018; Yonazi, Sol and Albert Boonstra, 2010) identifies that most egovernment systems in most developing countries are rolled-out by government without input from citizens. According to Schuppan (2009 these government-driven initiatives epitomise the failing point of most egovernment systems in Africa as citizens tend to shun them. Citizen-centric (Rana, Dwivedi, and Williams, 2013) and citizen-driven (Bwalya, 2018; Munyoka and Maharaj, 2017a; Otieno and Omwenga, 2016) approaches are some of the plausible modern trends to roll-out e-government systems in the $21^{\text {st }}$ century with a high probability of acceptance and utilization by citizens.

The focus of this study is on the G2C domain, investigating the effect of effort expectancy, price value, service quality, optimism bias and behavioural intention on citizens' decisions to use e-government systems in Zimbabwe. In the context of this study, e-government is an umbrella term referring to any electronic system

Reference this paper: Munyoka, W., 2019. Exploring the Factors Influencing E-Government use: Empirical Evidence from Zimbabwe. The Electronic Journal of Information Systems Evaluation, 22(2), pp. 78-91, available online at www.ejise.com 
used by citizens to access government services and include mobile-government, smart-government and electronic-government. Zimbabwe is a developing nation located in Sothern Africa and a member of the Southern African Development Community (SADC) with "complex dynamics rooted in politics, economy and social settings" (Ruhode, 2016, p. 1). Moreover, Zimbabwe is undergoing high cash shortage, high inflation, long queues for most commodities (including fuel, gas and some food items) and with most of the remaining operating industries shutting down. These conditions make Zimbabwe an interesting country to investigate; especially on how citizens perceive e-government as a preferred mode for accessing government services. Similarly, Munyoka and Maharaj (2019) posit that it will be exciting to establish how citizens react to government calls on using e-government systems in a country like Zimbabwe that is characterised with information censorship, reported security breaches and dwindling citizen trust on the governance processes. On another note, this study acknowledges that there are numerous studies (Verkijika and De Wet, 2018; Kyem, 2016; Munyoka and Maharaj, 2017a) that have addressed many other factors affecting e-government adoption and use by citizens in Southern Africa.

To start with, e-government by itself is a complex governance issue, often driven by the political-will and agendas aimed at achieving socio-economic development for a nation. Therefore, it is essential to understand how e-government systems come into being: firstly, through the supply-driven initiatives and secondly through people-driven endeavours. Supply-driven e-government projects are spearheaded by governments and sometimes with the assistance of international donor agencies with minimum citizen involvement in the decision-making process (Hafkin, 2009) and often associated with high failure rate, low acceptance and adoption by citizens. In contrast, people-driven e-government agenda values citizen input and participation regarding 'what' services are rolled-out (OECD, 2013). Recent trends (United Nations, 2018) suggest that egovernment should be aimed at addressing the sustainable agenda of the broader society to have a great impact. In most developing nations, Zimbabwe included, e-government adoption and use are generally voluntary and as such governments should understand the factors driving and impeding citizens' efforts (Kyem, 2016, Munyoka and Maharaj, 2017a). However, the prevailing economic conditions in Zimbabwe like cash shortage compel citizens to use mobile banking and e-payment to transact their daily services and payments. Drawing from the UTAUT2 model, this study is guided by the question 'how significant is each of the five factors in influencing one's decisions to use e-government systems in Zimbabwe?' Therefore, this study seeks:

- To establish the effect of effort expectancy on citizens' behavioural intention

- To establish the effect of price value on citizens' behavioural intention

- To establish the effect of service quality of e-government systems on citizens' behavioural intention

- To establish the effect of citizens' behavioural intention on use behaviour

- To establish the effect of optimism bias on citizens' use behaviour on e-government systems

This study, therefore, provides essential theoretical grounding and a conceptual framework that could be used by policy and decision makers to identify the weaknesses and strengths of e-government development in Zimbabwe and other developing nations with similar socio-economic settings. The rest of this paper is structured as follows: Section 2 presents the theoretical grounding and the conceptual framework for this study together with the eight suppositions; Section 3 presents the research methodology; The analysis and presentation of results are then presented, followed by the discussion, implications and limitations of the study, and suggestion for future research directions.

\section{Research Model}

\subsection{The Extended Unified Theory of Acceptance and Use of Technology (UTAUT2)}

This study is underpinned by the UTAUT2 (Venkatesh, Thong and Xu, 2012) model which conceptualise users' behavioural intention to use technological innovation (i.e. e-government system). Venkatesh, Thong and $\mathrm{Xu}$ (2012) suggests that a users' behaviour intention to adopt any technological innovation is influenced by seven determinant factors (performance expectancy, effort expectancy, social influence, facilitating conditions, hedonic motivation, price value and one's habits). The model identifies three moderating variables (age, gender and experience) to the seven determinant variables. The UTAUT2 model is a culmination of eight previous behavioural and technology acceptance models for predicting one's behavioural intention to adopt technology innovations. However, despite its wide usage in technology acceptance studies, some scholars (Alshehri et al., 2012; Fan and Yang, 2015) argues that the UTAUT2 model does not consider other pertinent 
factors such as service quality and optimism bias affecting citizens' intentions to adopt and use ICTs. As suggested by Venkatesh, Thong and Xu (2012), researchers have the freedom to adapt the UTAUT2 model through the addition or removal of constructs to suit different setups - thus, its strength and suitability for use in this study. Therefore, this study adapts the UTAUT2 model by incorporating service quality and optimism bias into the proposed conceptual model (see Figure 1). However, the other UTAUT2 determinant variables (facilitating conditions, performance expectancy, social influence, hedonic motivation and habits) and moderating factors (gender, age and experience) has been extensively investigated elsewhere (Qasem and Zolait, 2016; Munyoka and Maharaj, 2017a; Otieno and Omwenga, 2016) and (Munyoka and Maharaj, 2017b) respectively. Therefore, they are out of the scope of this study. According to Venkatesh, Thong and Xu (2012), the seven determinant factors of the UTAUT2 model can be defined as:

1. Effort expectancy (EE) measures how easy it is to use the system.

2. Performance expectancy (PE) measures the user's perception that using the system will be personally beneficial.

3. Facilitating Conditions ( $F C$ ) measures the user's belief that existing organisational infrastructure can support the use of the proposed system.

4. Social Influence (SI) measures the influence of others on the user's intention to use the system.

5. Hedonic Motivation (HM) refers to the pleasure derived from the use of technology.

6. Price Value (PV) refers to the cost and price structures of accessing an online service.

7. Habits $(H)$ measures the tendency of an individual to spontaneously perform certain behaviour after learning something.

\subsection{Conceptual Model}

Figure 1 presents the proposed research model for this study incorporating three constructs variables (effort expectancy, price value and service quality (SQ)) affecting a person's behavioural intention (BI) and three constructs (behavioural intention, service quality and optimism bias (OB)) affecting use behaviour (USE) on egovernment systems. Optimism bias measures a user's predisposition towards using a system despite his/her prior experiences (Carter et al., 2012). Service quality is the combined quality features associated with egovernment websites, services offered, and the accuracy, completeness, timeliness, conciseness, and relevancy of the information provided (Sharma, 2015).

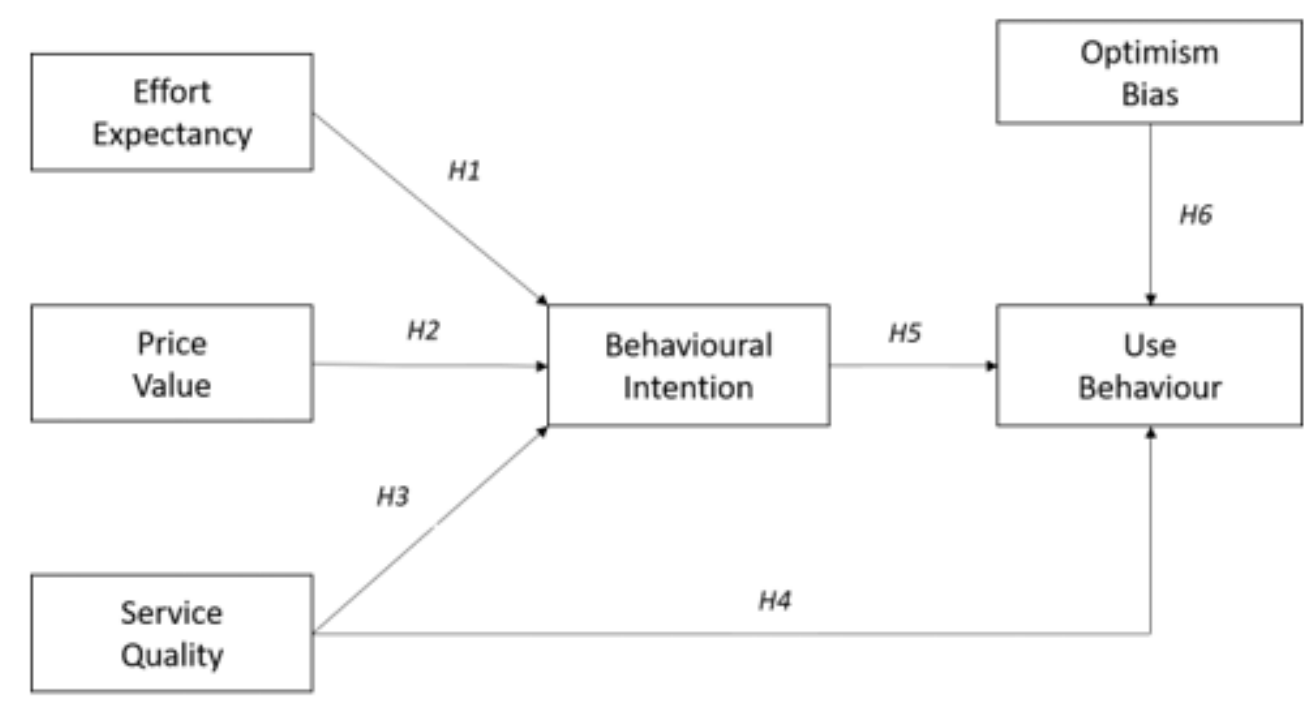

Figure 1: Research model

Based on the proposed model (Figure 1), the following hypotheses underpin this study:

H1 $_{0}$ : Effort expectancy does not influence one's behavioural intention to adopt e-government systems

$\boldsymbol{H 1}_{\boldsymbol{a}}$ : Effort expectancy influences one's behavioural intention to adopt e-government systems

$\boldsymbol{H}_{\mathbf{0}}$ : $\quad$ Price value associated with internet access does not influence one's behavioural intention to adopt egovernment systems. 
$\boldsymbol{H 2}_{\boldsymbol{a}}$ : Price value associated with internet access influences one's behavioural intention to adopt egovernment systems.

H3: Quality of services on e-government systems does not influence one's behavioural intention to adopt such systems.

$\boldsymbol{H 3}_{\boldsymbol{a}}$ : Quality of services on e-government systems influences one's behavioural intention to adopt such systems.

H4$_{0}$ : Quality of services does not influence one's decision to use e-government systems.

$H_{4_{a}}$ : Quality of services influences one's decision to use e-government systems.

H5: Citizens' behavioural intention to use e-government services does not lead to the continued utilisation of e-government systems.

$H_{\boldsymbol{a}}$ : Citizens' behavioural intention to use e-government services leads to the continued utilisation of egovernment systems.

H6: $\quad$ Optimism bias does not influence one's use behaviour in e-government systems.

$H_{\boldsymbol{a}}$ : Optimism bias influences one's use behaviour in e-government systems.

H7: Effort expectancy influences use behaviour mediated by behavioural intention.

H8: $\quad$ Price value influences use behaviour mediated by behavioural intention.

\section{Research methodology}

This study adopts a quantitative research approach; which involves the execution of the hypothetico-deductive approach. Creswell (2014) suggest that a quantitative research approach is the best approach for any research aimed at generalisation. Hence, its suitability and use in this study. Moreover, this approach is consistent with prior studies on e-government adoption that adapted the UTAUT model (Venkatesh et al., 2016; Al-Qeisi et al., 2015; Ami-Narh and Williams, 2012). The next sections discuss the procedures adopted in this study for instrument design, sample design, pilot study, data gathering and analysis procedures, and ethical considerations.

\subsection{Instrument Design}

The survey questionnaire for this study was designed based on the research model proposed in Figure 1. The constructs of the survey instrument were adapted from prior studies on technology acceptance studies and the United Nations e-government survey database and adapted to the context of this study. The survey questionnaire of this study had two major sections. Section A solicited for demographic-related information of the participants (i.e. gender, age, level of education and occupational status). Section B of the questionnaire focused on information pertaining to the dependent variables (behavioural intention and use behaviour) and independent variables (effort expectancy, price value, service quality and optimism bias) of this study. All construct items used a five-point Likert scale ranging from strongly disagree to strongly agree.

\subsection{Sample Design}

The target population for this study were confined to individual citizens' perceptions and lived experiences with e-government systems in Zimbabwe. The study used a respondent-driven sampling (RDS) strategy to collect quantitative data from 600 e-government user participants from five provinces (Harare Province, Mashonaland East, Mashonaland Central, Masvingo and Matabeleland South) in Zimbabwe. Heckathorn (1997) RDS is a chain-referral, link-tracing network sampling method used in situations where traditional sampling methods do not yield desired results i.e. in hard-to-find, invisible and marginalised population. Data for this study were collected over six months starting from September 2017 to February 2018. The RDS was done in three phases as suggested by Heckathorn (1997). In the first formative phase, the adequacy and networking of the population was assessed. Diversified set informants (i.e. seeds) were purposively identifies with the assistance of local government agencies. Survey questionnaires and coupons were designed and ready for distribution. The coupons had a unique number (used to track each participant), name and contact details of the researcher, purpose of the study, written in the vernacular language used in each specific region and blank space for the respondent to write his/her contact details.

In the second recruitment phase, 3 informants (constituted of traditional chiefs, Econet shop-operators, school headmasters, municipality front officers, university deans) were identified as seeds for each province. Each seed identifies 3 to 5 other informants (Heckathorn, 2002) who were using e-government systems, were ready to participate and give them coupons. The goal of the recruitment phase was to create a long and 
representative referral chain ('wave') so that the final sample was independent of the seeds and reflective of the entire recruiting network population.

The third analysis phase establishes weights according to the size of the sub-networks created by each of the initial 15 seeds across the five provinces. Wave1 recruited 55 participants, 165 participants in wave2, 495 in wave3, and 105 in wave4. At this point, each subsequent wave was generating fewer informants than the previous stage, thus reaching the equilibrium point. The sampling process was stopped since it was now representative (Salganik, 2006). In line with Johnston and Sabin's (2010, p. 40) suggestion, it is at the equilibrium point that the sample composition becomes independent of the seeds done at various waves and in that way, "overcoming any biases introduced by the non-random selection of seeds." In total 600 participants were generated, and the survey questionnaires were self-administered by the researcher using the participant contact details provided on the coupons and the social network size per province.

\subsection{Pilot Study}

Prior to conducting the main study, a pilot study was administered to twelve randomly selected respondents in three different cities in Zimbabwe. The primary objective for administering this pilot study was to ascertain whether the respondents would comprehend the questions and instructions given on the survey instrument. The minor aspects raised by the respondents pertaining to spelling and grammatical and instructional errors were incorporated into the final survey questionnaire.

\subsection{Data Gathering and Analysis Procedures}

A self-administered survey questionnaire was the primary instrument used for data gathering in this study. In total, 489 usable questionnaires were received out of the possible 600 distributed, giving an $81.5 \%$ response rate. The overall response rate for this study is considered more than adequate, especially given that the recommended acceptable response rate for a survey is $30 \%$ (Sekaran and Bougie, 2016). IBM Statistical Package for Social Sciences (SPSS) latest version was used to perform simple data analysis like descriptive statistics to gain an in-depth understanding of the data, in-line with each construct. Further data cleaning and screening procedures were carried out to test for univariate normality using Kolmogorov-Smirnov and ShapiroWilk tests, and to test for common methods bias using Harman's single factor test. IBM Amos version 26 for Windows was used to test the hypotheses for this study using structural equation modelling (SEM). SEM is a statistical analysis technique that makes use of confirmatory factor analysis (CFA) to establish the fit of the proposed research model. In this study, CFA using SEM was done in three phases in-line with Hair's et al. (2018) suggestion. In the first phase, tests for the measurement model to establish discriminant and convergent validity of the constructs were done. The second phase involved establishing the overall fit of the structural model using several fit indices. The third and final phase involved path coefficients and hypotheses testing.

\subsection{Ethical Considerations}

Prior to the pilot study and data gathering, ethical clearance was sought and obtained. Moreover, all protocols and code of ethics stipulated by the ethical clearance were followed. Before completing the survey questionnaire, all respondents were asked to sign an informed consent letter stipulating that their participation in this study was voluntary with no financial rewards, that whatever information they provided was treated as confidential and was going to be solely used for academic purpose. A cover letter and coupons were also presented to respondents outlining the purpose of this study.

\section{Data Analysis and Results}

\subsection{Descriptive Statistics}

Table 1 presents the profile of the 489 respondents. Most of the respondents were male (53.8\%), whilst the dominant age group ranges between 25 and 34 years. Moreover, many of the respondents (28.1\%) possessed a first university degree; while the largest percentage $(42.9 \%)$ was unemployed. This finding concurs with Bhebhe, Bhebhe and Bhebhe (2016) who reported that most of the working age group (18 - 65) in Zimbabwe were either self-employed or unemployed. 
Table 1: Profile of Respondents

\begin{tabular}{|c|c|c|c|}
\hline Moderator Factor & Moderator Variable & Frequency & Percentage \\
\hline \multirow[t]{2}{*}{ Gender } & Female & 230 & 46.2 \\
\hline & Male & 268 & 53.8 \\
\hline \multirow{6}{*}{ Age } & $15-24$ & 98 & 19.6 \\
\hline & $25-34$ & 156 & 31.4 \\
\hline & $35-44$ & 127 & 25.5 \\
\hline & $45-54$ & 72 & 14.5 \\
\hline & $55-64$ & 39 & 7.8 \\
\hline & Above 65 & 6 & 1.2 \\
\hline \multirow{6}{*}{ Education Qualifications } & Others & 79 & 15.9 \\
\hline & Certificate & 103 & 20.7 \\
\hline & Diploma & 121 & 24.3 \\
\hline & Degree & 140 & 28.1 \\
\hline & Masters & 46 & 9.2 \\
\hline & Doctorate & 9 & 1.8 \\
\hline \multirow{5}{*}{ Occupational-Status } & Unemployed & 210 & 42.9 \\
\hline & Employed & 39 & 8.0 \\
\hline & Self-Employed & 178 & 36.4 \\
\hline & Student & 51 & 10.4 \\
\hline & Other & 11 & 2.2 \\
\hline
\end{tabular}

\subsection{Data Cleaning and Screening Procedures}

Prior to data analysis, all incomplete or wrongly completed questionnaires were screened-out leaving 489 suitable for data analysis. Alshehri (2012) suggest that before doing any advanced statistical analysis like regression analysis or structural equation modelling, data should first be tested for homogeneity to establish data distribution for all the variables in-line with the normal distribution. In this study, Kolmogorov-Smirnov and Shapiro-Wilk tests for normality were conducted to test the skewness and kurtosis of the data sets. Figure 2 illustrates the distribution of the mean and standard deviation of the service quality dataset. The histogram shows that the data on the service quality was shifted to the left, i.e. positively skewed - thus, not following the normal Gaussian distribution (with residual scores concentrated on the 2.72 mean score). Likewise, the behavioural intention construct was also negatively skewed and was normalised.

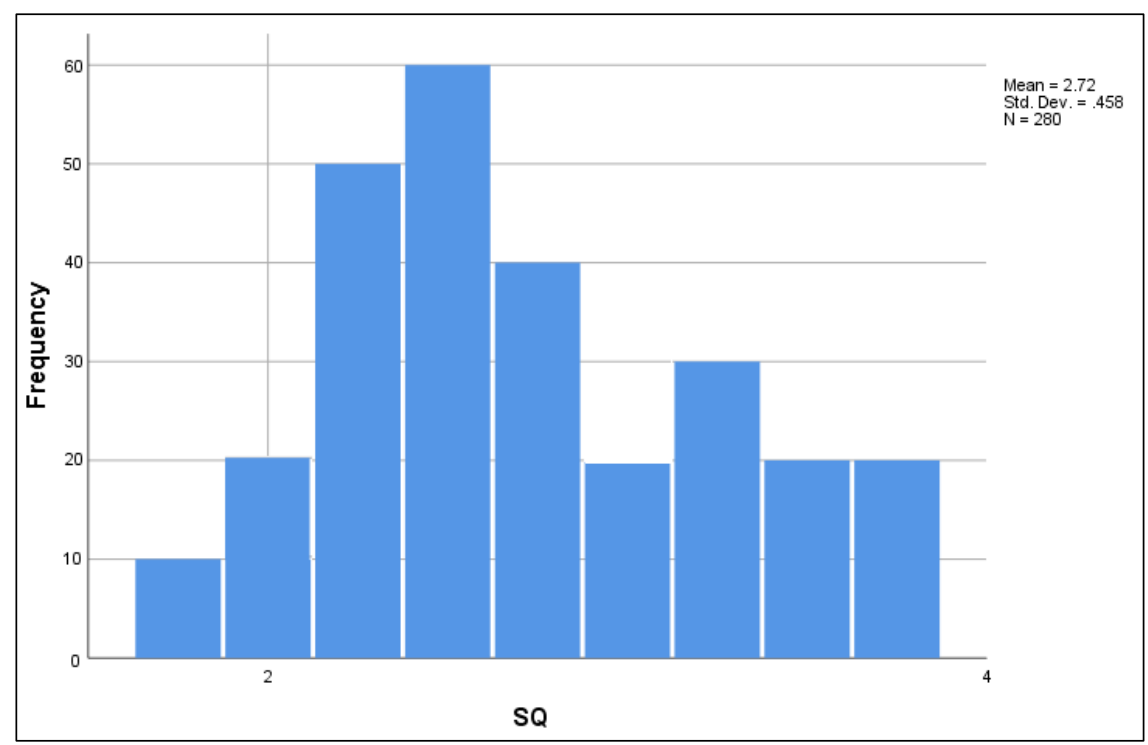

Figure 2: Histogram on Service Quality data set 
To resolve this anomaly in data distribution, box-plots (Figure 3) were generated to identify the outliers i.e. 92, 265 and 276 for SQ, and 369 for BI. As an advanced statistical analysis, SEM should meet multivariate normal distribution for the data, since non-normal data distributions may distort the goodness of fit indices and the overall results (Karakaya-Ozyer and Aksu-Dunya, 2018). To deal with the identified outliers and in-line with Aguinis, Gottfredson and Joo's (2013) suggestion, the researcher created rules in the IBM SPSS to exclude the identified outliers for the two constructs of SQ and BI, i.e. "BI < = 369" to exclude all measures above 369 for the behavioural intention from further analysis.

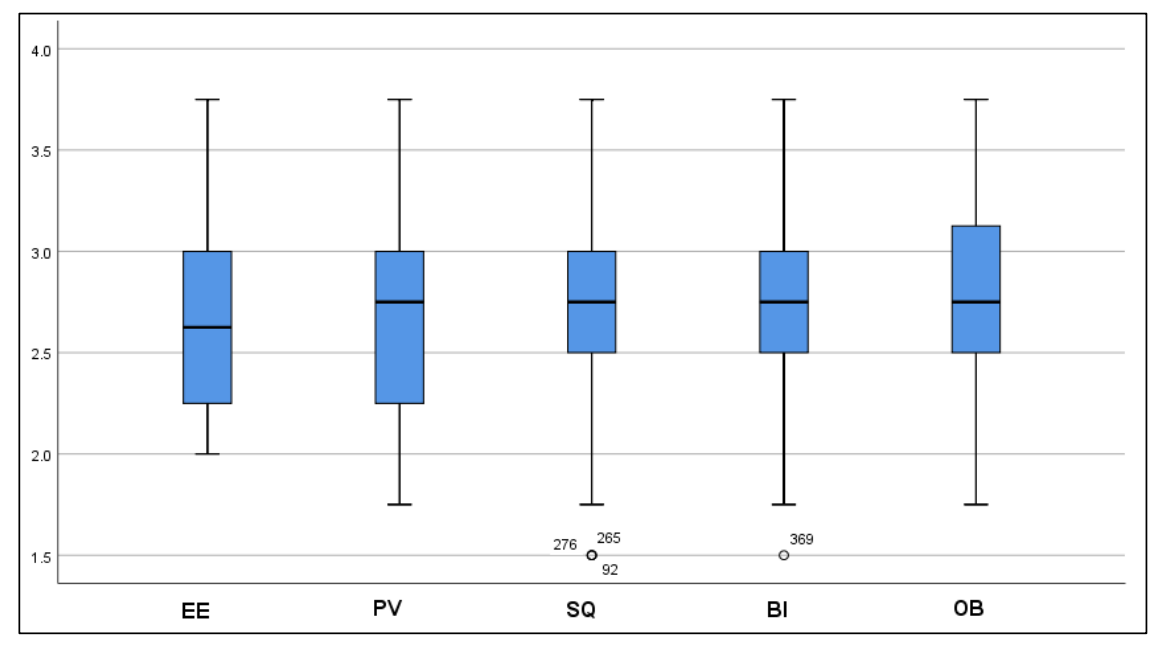

Figure 3: Boxplots for the datasets

Table 2 illustrates the results for normality tests done on all the measured items using the KolmogorovSmirnov (K-S test) and the Shapiro-Wilk test after the identified non-normal datasets (see Figure 3) were filtered out. Thus, all the measured items were significant ( $p$-value $=0.000$ ) for both the K-S and Shapiro-Wilk tests (Table 2).

Table 2: Normality Test for all the measured items

\begin{tabular}{|c|c|c|c|c|c|c|}
\hline \multirow[b]{2}{*}{ Measured Items } & \multicolumn{3}{|c|}{ Kolmogorov-Smirnov ${ }^{a}$} & \multicolumn{3}{|c|}{ Shapiro-Wilk } \\
\hline & Statistic & $\mathrm{df}$ & Sig. & Statistic & $\mathrm{df}$ & Sig. \\
\hline $\mathrm{EE}$ & .141 & 300 & .000 & .898 & 300 & .000 \\
\hline PV & .135 & 289 & .000 & .904 & 289 & .000 \\
\hline SQ & .139 & 299 & .000 & .967 & 299 & .000 \\
\hline $\mathrm{BI}$ & .140 & 299 & .000 & .967 & 299 & .000 \\
\hline $\mathrm{OB}$ & .138 & 293 & .000 & .968 & 293 & .000 \\
\hline USE & .147 & 311 & .000 & .968 & 311 & .000 \\
\hline
\end{tabular}

a. Lilliefors Significance Correction

Where,

$\mathbf{E E}=$ Effort Expectancy; PV = Price Value; SQ = Service Quality; $\mathbf{B I}=$ Behavioural Intention; $\mathbf{O B}=$ Optimism Bias; USE = Actual use of e-government system

The independent and dependent variables for this study were measured using the same survey questionnaire and thus, there was a potential for common methods bias. Harman's single factor test was used to test for common methods bias by determining if the first principal component explains less than $50 \%$ of the total variance (Mudzana and Maharaj, 2017). Findings of this study show that only $12.572 \%$ of the total variance was explained when the first component was extracted. Thus, a significant amount of variance was explained by the unextracted factors. Therefore, common methods bias was not an issue in this study and no further steps were taken to address it. 


\subsection{Reliability Analysis}

The Cronbach's (1951) Alpha reliability results for this study (Table 3) shows that the study instrument achieved the right internal construct reliability scores with all values above the recommended cut off value of 0.70 .

Table 3: Cronbach's Alpha Reliability Results

\begin{tabular}{|l|c|c|c|}
\hline \multicolumn{1}{|c|}{ Constructs } & $\begin{array}{c}\text { No. of } \\
\text { items }\end{array}$ & $\begin{array}{c}\text { Cronbach's } \\
\text { Alpha }(\boldsymbol{\alpha})\end{array}$ & $\begin{array}{c}\text { Comments (based on Hair's et al. (2018) } \\
\text { reliability scales) }\end{array}$ \\
\hline Effort Expectancy (EE) & 4 & 0.712 & High Reliability \\
\hline Price Value (PV) & 4 & 0.807 & High Reliability \\
\hline Quality of Services (QS) & 5 & 0.863 & High Reliability \\
\hline Behavioural Intention (BI) & 3 & 0.702 & High Reliability \\
\hline Optimism Bias (OB) & 4 & 0.823 & High Reliability \\
\hline Use Behaviour (USE) & 3 & 0.891 & \\
\hline
\end{tabular}

\subsection{Measurement Model}

Structural Equation Modelling (SEM) using IBM AMOS was used to establish the measurement model (testing discriminant and convergent validity of the measurement scales) and to determine how the model fits the collected data. Two tests; construct reliability and average variance extracted (AVE) were used to assess the convergent validity of the constructs. AVE measures the level of variance captured by a construct versus the level due to measurement error and values above 0.70 are considered very good, whereas, the levels between 0.50 and 0.69 are considered good (Henseler, Ringle and Sarstedt, 2015). AVE values for all the constructs (EE $=.657 ; \mathrm{PV}=.701 ; \mathrm{QS}=.689 ; \mathrm{BI}=.771 ; \mathrm{OB}=.815 ; \mathrm{USE}=.791$ ) were above the minimum recommended threshold value of 0.50 . Thus, confirming that the constructs of the proposed model explained more than $50 \%$ of variances of the construct items.

Discriminant validity (Hair et al., 2018) was carried out in this study to establish and ensure that each construct of the study instrument was empirically unique from the rest of the other constructs and characterises phenomena of interest in the structural equation model. AlKhatib (2013) suggest a rigorous method for determining discriminant validity in which the absolute values of correlations between the constructs are compared with the square root of the AVE for that specific construct. The rule of thumb according to AlKhatib (2013) is that the square root of the AVE for that specific construct should always be greater than the AVE and all the correlations with all the other constructs. Table 4 indicates that the square roots $(\dagger)$ for all constructs were greater than the associated correlations for all the other constructs; thus, there were no concerns with the discriminant validity. Based on this finding, it can be deduced that CFA results provided acceptable discriminant and convergent validity for the construct scales of the questionnaire.

Table 4: Standardised Construct Correlation Matrix

\begin{tabular}{|c|c|c|c|c|c|c|}
\hline & $\mathrm{EE}$ & PV & QS & OB & BI & USE \\
\hline $\mathrm{EE}$ & $.81^{\dagger}$ & & & & & \\
\hline PV & $.631^{* *}$ & $.84^{\dagger}$ & & & & \\
\hline QS & .077 & $.341^{*}$ & $.83^{\dagger}$ & & & \\
\hline OB & .068 & $.135^{* *}$ & $.191^{*}$ & $.90^{+}$ & & \\
\hline $\mathrm{BI}$ & -.089 & $.261^{* *}$ & $.168^{*}$ & .039 & $.88^{+}$ & \\
\hline USE & $.356^{* *}$ & $.482^{* *}$ & $.270^{*}$ & $.641^{* *}$ & $.699^{* *}$ & $.89^{+}$ \\
\hline
\end{tabular}

\subsection{Structural Model}

The major goal of applying structural equation modelling is to establish the overall fit of the structural model. As suggested by Hair et al. (2018) this study used several fit indices to establish the overall fit of the structural model; Chi-Square $\left(\chi^{2}\right)$, goodness-of-fit index $(\mathrm{GFI})$, normed-fit index (NFI), comparative fit index (CFI), index of fit (IFI), Tucker-Lewis index (TLI), adjusted-goodness-of-fit index (AGFI) and the root-mean-square-error of 
approximation (RMSEA). The overall value of the Chi-Square $\left(\chi^{2}\right)$ for the final structural model was 431.12 with 247 degrees of freedom and with a significant $p$-value $=0.001$. Table 5 shows that after several iterations, all indices for the final structural model were above the minimum recommended values - thus demonstrating a good fit of the proposed research model.

Table 5: Summary of Overall Fit Indices for the Structural Model

\begin{tabular}{|l|l|c|c|}
\hline \multicolumn{1}{|c|}{ Absolute Fit Index } & \multicolumn{1}{|c|}{$\begin{array}{c}\text { Recommended } \\
\text { cut-off value }\end{array}$} & First Structural Model & Final Structural Model \\
\hline$p$ & $p$-value $<0.05$ & 0.04 & 0.001 \\
\hline$\chi^{2}$ & $\mathrm{~N} / \mathrm{a}$ & 463.57 & 431.12 \\
\hline$\chi^{2} / \mathrm{df}$ & $1<\mathrm{df}<3$ & 1.69 & 2.71 \\
\hline $\mathrm{Df}$ & $\mathrm{df} \geq 0$ & 230 & 0.920 \\
\hline GFI & $\geq 0.90$ & 0.892 & 0.901 \\
\hline AGFI & $\geq 0.80$ & 0.890 & 0.904 \\
\hline CFI & $\geq 0.90$ & 0.900 & 0.978 \\
\hline NFI & $\geq 0.90$ & 0.961 & 0.969 \\
\hline IFI & $\geq 0.95$ & 0.948 & 0.959 \\
\hline TLI & $\geq 0.95$ & 0.950 & 0.043 \\
\hline RMSEA & $<0.08$ (good fit) or $<0.05$ & 0.068 & \\
\hline
\end{tabular}

\subsection{Path Coefficients and Hypotheses Testing}

Table 6 presents a summary of the hypotheses testing. According to Hair's et al. (2018) the parameter coefficient value is statistically significant (at $p<0.05$ level) when it's critical ratio (C.R.)/t-value for a standardised regression weight is greater than 1.96. Table 6 shows that hypotheses $\left(H 1_{0}, H 2_{a}, H 3_{0}, H 4_{a}, H 5_{a}\right.$, $\mathrm{HG}_{\mathrm{a}}$, and $\mathrm{H8}$ ) had all their critical ratios above 1.96 with significant levels below 0.05 . Therefore, hypotheses $\left(\mathrm{H} 1_{\mathrm{a}}, \mathrm{H} 2_{0}, \mathrm{H} 3_{\mathrm{a}}, \mathrm{H} 4_{0}, \mathrm{H} 5_{0}, \mathrm{H} 6_{0}\right.$, and $\left.\mathrm{H} 7\right)$ were rejected for not meeting this criterion.

Table 6: Summary of Hypotheses Testing

\begin{tabular}{|c|c|c|c|c|c|c|c|}
\hline $\begin{array}{l}\text { Hypothesis } \\
\text { Number }\end{array}$ & $\begin{array}{l}\text { Hypothesis } \\
\text { Path }\end{array}$ & Estimate & S. E & C.R & B & $p$-value & $\begin{array}{l}\text { Hypothesis } \\
\text { Supported by } \\
\text { Findings? }\end{array}$ \\
\hline$H 1_{0}$ & $\mathrm{EE} \rightarrow \mathrm{BI}$ & .64 & .15 & 4.27 & .69 & $* * *$ & yes \\
\hline $\mathrm{Hz}_{\mathrm{a}}$ & $\mathrm{PV} \rightarrow \mathrm{BI}$ & .61 & .20 & 3.05 & .73 & $* * *$ & yes \\
\hline $\mathrm{H3}_{0}$ & $\mathrm{QS} \rightarrow \mathrm{BI}$ & .56 & .22 & 2.55 & .71 & $.03 *$ & yes \\
\hline $\mathrm{H} 4_{\mathrm{a}}$ & $\mathrm{QS} \rightarrow$ USE & .50 & .09 & 5.55 & .70 & $* * *$ & yes \\
\hline H5a & $\mathrm{BI} \rightarrow$ USE & .46 & .07 & 6.60 & .89 & $* * *$ & yes \\
\hline$H 6_{a}$ & $\mathrm{OB} \rightarrow$ USE & .88 & .19 & 4.63 & .77 & $.01 * *$ & yes \\
\hline $\mathrm{H7}$ & $\mathrm{EE} \rightarrow \mathrm{BI} \rightarrow \mathrm{USE}$ & .33 & .31 & 1.08 & .24 & .062 & no \\
\hline H8 & $\mathrm{PV} \rightarrow \mathrm{BI} \rightarrow$ USE & .65 & .11 & 5.91 & .87 & $* * *$ & yes \\
\hline
\end{tabular}

Therefore, based on the findings in Table 6, the following interpretations can be presented:

H10: Perceived ease of use had no effect on citizens' behavioural intention to use e-government systems.

$\mathrm{H} 2 \mathrm{a}$ : As the cost of accessing the internet increases adoption propensity decreases.

H30: Quality of services on e-government systems had no effect on one's tendencies to adopt such systems.

H4a: Better quality of services lead to increased use.

H5a: An increase in behavioural intention leads to increased use.

H6a: Greater optimism bias leads to increased use. 
H7: Behavioural intention had no mediating effect between effort expectancy and use behaviour. H8: Behavioural intention had a mediating effect between price value and use behaviour.

Figure 4 shows that 89 per cent of the discrepancies among the four endogenous constructs (price value, service quality, optimism bias and behavioural intention) were explained by the use behaviour on egovernment systems. This shows that the proposed model has good predictive power (Hair et al., 2018) of the use behaviour of e-government systems in Zimbabwe.

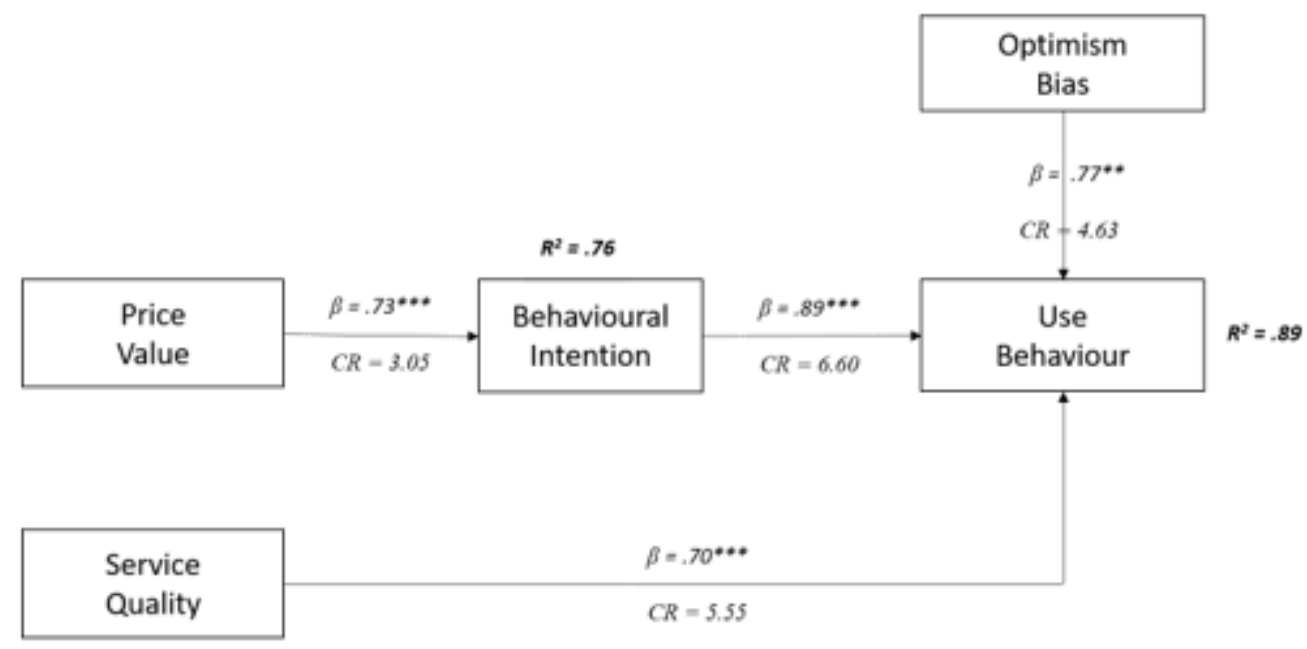

Figure 4: Research model with Standardised Coefficient Paths

\section{Discussion and implications}

This study was aimed at determining the effects of five latent constructs ( $E E, P V, S Q, O B$ and $B I$ ) on citizens' use behaviour on e-government systems in Zimbabwe. To realise this aim, this study postulated eight propositions to validate the proposed conceptual model. The uniqueness of this study is that under the newly elected Zimbabwean government dispensation, the economy seems declining and cash shortage deepening yet citizens have no options, but to continue using the same government services. Therefore, studying the effect of these factors on citizens' actions towards e-government adoption and use becomes pertinent under such excruciating socio-economic conditions.

Despite an almost stagnating to a declining economy, private mobile service companies and the government of Zimbabwe are making inroads in providing mobile services and e-government services to the public. Most of the respondents claimed to have used e-payment (i.e. Ecocash, mobile payment) to pay municipality bills, electricity purchase, online passport application and payment system, ZimConnect (for registering companies and buying and renewing car license discs) and e-health systems. Most respondents claimed that the recently introduce $2 \%$ tax levy on every e-payment transaction or money transfer for any amount above USD\$10 by the government negatively affected their budgets. Furthermore, a 150\% increase per litre of fuel levy in January 2019 followed by another 47\% in May hard-hit the general cost of living and distort the market forces. These measures had negative ripple effects on all transported goods and commodity prices - thus, inevitably impoverishing the consumers.

Consistent with previous studies (Alsaif, 2013; Chau and Hu, 2002) on e-government adoption, findings of this study show that effort expectancy is negatively linked to behavioural intention for early adopters and to use behaviour for experienced users. However, our findings were unexpected and contradict with findings of previous studies (Venkatesh et al., 2003; Samuel, 2014) who established effort expectancy as a salient factor in the early days of technology use, especially for those users with limited internet experience and becomes nonsignificant over periods of extended and sustained use. One plausible explanation for these findings could be that most of the respondents to this study were using short messaging services (SMS) cell phone-based services like Ecocash which is relatively easy to use for most literate citizens and often there are agency outlets across Zimbabwe to assist users. 
This study revealed that citizens regarded price value (costs) associated with internet charges and recharging of mobile data bundles and airtime as crucial determinants of both behavioural intention and use behaviour. These findings were expected, especially against the background that Zimbabwe is currently experiencing high inflation, high unemployment levels and the recently introduced $2 \%$ tax levy for every online payment transaction or transfer above USD\$10. Moreover, the dire cash shortage in Zimbabwe meant that most citizens are compelled to use e-payment systems to pay for government services. Under such conditions, citizens value their money, thus, why the price value construct had a positive and significant effect on e-government users. This finding concurs with findings of Venkatesh, Thong and $X u$ (2012) who established that in the consumer context users are sensitive to prices of products and services; and hence will be more cost-conscious.

The quality of features and services associated with e-government websites, i.e. the accuracy, completeness, timeliness, conciseness, and relevancy of the information provided were found to be pertinent elements that encouraged citizens to use e-government systems. A significant positive relationship between service quality and use behaviour was established in this study. Most of the respondents felt enticed to use e-government websites with current information that is easily accessible. This finding reaffirms results of prior research (Sá, Rocha and Cota, 2016; Fan and Yang, 2015; Detlor et al., 2013) that accentuates the incorporation of quality web features as paramount for stimulating the use of e-government systems. However, this study could not establish any correlation between service quality and behavioural intention. A possible explanation for this is drawn from Alshehri et al. (2012) who suggests that quality of services on e-government systems is pertinent to citizens who already have some experience in using such systems (as they have a basis of comparison between prior experiences and expectations) and less relevant to those with no knowledge.

The behavioural intention had a positive and significant effect on use behaviour. Citizens who perceive egovernment systems as valuable were more motivated to use such systems. Findings of this study are consistent with the UTAUT theoretical argument and previous studies (Alkhatib, 2013; Venkatesh et al., 2003) which confirmed behavioural intention as a strong predictor of use behaviour.

Findings of this study confirmed optimism bias as having a positive and significant effect on use behaviour. Despite having some scanty issues with the quality of services and high service charges per e-government transaction, citizens who regarded themselves as technologically savvy compared to the average users remains motivated to use such systems. The results of this study reaffirm the empirical findings by Carlin (2016). A plausible explanation for such results is that as users become competent, familiar with using and reliant on using e-government systems, they will be inclined to keep on using such systems. Moreover, considering the prevailing shortage of cash in circulation, most citizens have no option but to use e-payment system for government services.

\subsection{Implications}

This study has implications in three spheres. Firstly, the study contributes to the existing corpus of literature on e-government adoption by adapting the UTAUT model and applying it to the Zimbabwean context with its rich and complex socio-economic set-up: thus, empirically contributing to theory building and testing. The findings of this study reaffirm as true some of the previously theorised technology acceptance and use relationships (Venkatesh et al., 2012; Ami-Narh and Williams, 2012) by shedding more light on some critical factors affecting and contribute to the successful adoption and use of e-government in Zimbabwe and other developing countries with similar socio-economic conditions. The author argues that to date there are very few studies (Maharaj and Munyoka, 2019; Manenji and Marufu, 2016) done that empirically test the utilisation of e-government systems by citizens in the context of Zimbabwe. Therefore, this study is expected to elevate the discourse of e-government adoption and utilisation by citizens in developing nations by adding new constructs like service quality and optimism bias which never existed in the original technology acceptance and use models and not covered by most prior studies (Furusa and Coleman, 2018; Rajah, 2015).

Secondly, regarding practical implications, the findings of this study could have implications for ICT and egovernment policy formulation and implementation. In fact, at policy formulation and system design stages, users should be engaged for input regarding what they would prefer on the systems and what frustrates them in other existing e-government systems to increase user acceptance. Similarly, to increase adoption and use of e-government systems, designers of these systems should provide quality services. This could be done, for example by ensuring that manual and online forms are similar. These notions are in accord with Mellouli, Bentahar and Bidan (2016) who suggests that without mechanisms in place to felicitate e-government 
adoption, quality of services on e-government systems would benefit the minority of citizens and thus, making e-government a mode for digital and socio-economic divide. Thirdly, to access e-government, one should have access to the internet. Yet, the cost of accessing the internet is quite expensive for most of the unemployed Zimbabweans. Therefore, this study recommends that policy formulators and decision-makers on ICT, internet costs and finance should consider the prevailing economic climate when determining the price structures of such services. Overcharging the price for accessing the internet and e-government services may negatively affect citizens' attitudes and capacity towards using such services.

\subsection{Limitations and Future Research Direction}

Despite having achieved its aim and made contributions to both theory and practice; this study has its limitations that should be considered for future research. On the methodological frontier, the conceptual model considered the effect of only five constructs on citizens' use behaviour on e-government systems in the context of Zimbabwe. Going forward, more constructs and moderating variables like age, gender and experience in use should be investigated and a comparison made with other countries with similar socioeconomic conditions to enable the generalisation of the findings. Therefore, care should be taken when trying to generalise the findings of this study to other developing nations. The use of respondent-driven sampling (RDS) strategy in identifying e-government users was exciting, yet it also presented some challenges regarding how to motivate the informants to participate since participation was voluntary and without financial incentives. Thus, this approach works best for non-governmental organisations which often offers financial and material rewards to induce participation as opposed to purely non-incentivised academic surveys like the current study. Whilst the quantitative research approach adopted in this study provides a comprehensive statistical analysis using structural equation modelling, a mixed methods research approach could have provided a more pragmatic approach and a voice from the respondents regarding e-government adoption in Zimbabwe.

\section{Conclusions}

This study examined the effect of five variables (effort expectancy, price value, service quality, optimism bias and behavioural intention) on participants' use behaviour on e-government in Zimbabwe. This research draws from the UTAUT2 model to advance a conceptual model used to establish the effect of these five latent variables on1 e-government systems. A field survey for testing the proposed model was conducted in Zimbabwe from 489 respondents. This study attempted to bridge existing theoretical, methodological and practice gaps in e-government in Zimbabwe. The results showed that price value associated with internet access and charges on e-government transactions had a positive significant effect on both citizens' behavioural intention to adopt and use behaviour on e-government systems. Moreover, optimism bias exhibited one of the strongest effects on use behaviour after the behavioural intention. To encourage e-government adoption, the government should ensure that the information and services provided on e-government websites are accurate, complete, timely, concise and relevant to users. The findings show that effort expectancy had no significant effect on both behavioural intention and use behaviour on e-government in the Zimbabwean context. An understanding of these factors and their impact on citizens' use behaviour is crucial to policy makers, administrators and practitioners when rolling out e-government systems in-line with citizens' requirements. Accordingly, such an approach goes a long way towards e-government acceptance by users. The prevailing economic, social, political, and cultural circumstances in Zimbabwe are unique to its settings and as such caution should be taken in generalising findings of this study to other developing nations. Moreover, the proposed conceptual framework provides a theoretical lens and a vantage point for tackling the research question and the eight hypotheses, without necessarily considering all the possible factors affecting egovernment adoption in Zimbabwe. Going forward, more latent variables could be considered, and the context of study broadened to other Southern African countries with similar socio-economic conditions to enable generalisation.

\section{References}

Aguinis, H., Gottfredson, R.K. and Joo, H., 2013. Best-practice recommendations for defining, identifying, and handling outliers. Organizational Research Methods, 16(2), pp.270-301.

AlKhatib, H., 2013. E-government systems success and user acceptance in developing countries: The role of perceived support quality. PhD. Brunel Business School.

Ami-Narh, J.T. and Williams, P.A.H., 2012. A revised UTAUT model to investigate E-health acceptance of health professionals in Africa. Journal of Emerging Trends in Computing and Information Sciences, 3(10), pp. 1383-1391. 
Al-Qeisi, K., Dennis, C., Hegazy, A. and Abbad, M., 2015. How Viable Is the UTAUT Model in a Non-Western Context? International Business Research, 8(2), pp. 204-219.

Alshehri, M.A., 2012. Using the UTAUT Model to Determine Factors Affecting Acceptance and Use of E-Government Services in the United Kingdom of Saudi Arabia. PhD. Griffith University.

Alshehri, M., Drew, S., Alhussain, T. and Alghamdi. R.A., 2012. The Effects of Website Quality on Adoption of E-Government Service: An Empirical Study Applying the UTAUT Model Using SEM. $23^{\text {rd }}$ Australasian Conference on Information Systems, Geelong, Australia, 3-5 Dec 2012. Deakin University.

Alsaif, M., 2013. Factors affecting citizens' adoption of e-government moderated by socio-cultural values in Saudi Arabia. PhD. University of Birmingham.

Bhebhe, T.B., Bhebhe, R.K. and Bhebhe, B.S., 2016. An investigation into the causes of unemployment among youths in the city of Harare. Global Journal of Arts, Humanities and Social Sciences, 4(2), pp. 90-102

Bwalya, K.J., 2018, Decolonisation of e-Government Research and Practice: Exploring Contextual Issues and Opportunities in Africa, pp. i-330, AOSIS, Cape Town.

Carlin, J.P., 2016. Detect, disrupt, deter: A whole-of-government approach to national security cyber threats. Harvard National Security Journal, 7, pp. 391-436.

Carter, L., Schaupp, L.C., Hobbs, J. and Campbell, R., 2012. E-government utilization: understanding the impact of reputation and risk. International Journal of Electronic Government Research, 8(1), pp. 83-97.

Chau, P.Y.K. and Hu, P.J.H., 2002. Information Technology Acceptance by Individual Professionals: A Model Comparison Approach. Decision Sciences, 32(4), pp. 699-719.

Creswell, J.W., 2014. Research design: Qualitative, quantitative and mixed methods approaches, $4^{\text {th }}$ ed. London: SAGE Publications

Cronbach, L.J., 1951. Coefficient Alpha and the internal structure of tests. Psychometrika, 16(3), pp. 297-334.

Detlor, B., Hupfer, M.E., Ruhi, U. and Zhao, L., 2013. Information Quality and Community Municipal Portal Use. Government Information Quarterly, 30(1), pp. 23-32.

Fan, J. and Yang, W., 2015. Study on E-Government Services Quality: The Integration of Online and Offline Services. Journal of Industrial Engineering and Management, 8(3), pp. 693-718.

Furusa, S.S. and Coleman, A., 2018. Factors influencing e-health implementation by medical doctors in public hospitals in Zimbabwe. South African Journal of Information Management, 20(1), pp.1-9.

Heckathorn, D.D., 2002. Respondent-driven sampling II: deriving valid population estimates from Chain-Referral samples of hidden populations. Sociological Problems, 49(1), pp. 11-34.

Heckathorn, D.D., 1997. Respondent-driven sampling: A new approach to the study of hidden populations. Sociological Problems, 44(2), pp. 174-199.

Hafkin, N.J., 2009. E-government in Africa: An overview of progress made and challenges ahead. In Prepared for the UNDESA/UNPAN workshop on the electronic/mobile government in Africa: Building Capacity in Knowledge Management through Partnership. United Nations Economic Commission for Africa (pp. 17-19).

Hair, J. F., Black, W. C., Babin, B. J. and Anderson, R. E., 2018. Multivariate data analysis. $8^{\text {th }}$ ed. Harlow: Pearson Publishers.

Henseler, J., Ringle, C.M. and Sarstedt, M., 2015. A new criterion for assessing discriminant validity in variance-based structural equation modelling. Journal of the Academy of Marketing Science, 43(1), pp. 115-135.

Jain, P. and Akakandelwa, A., 2014. Adoption of e-government in Africa: challenges and recommendations. In Digital Access and E-Government: Perspectives from Developing and Emerging Countries (pp. 101-124). IGI Global.

Johnston, L.G. and Sabin, K., 2010. Sampling hard-to-reach populations with respondent-driven sampling. Methodological innovations online, 5(2), pp.38-48.

Kalamatianou, M.A. and Malamateniou, F., 2017. An Extended UTAUT2 Model for e-Government Project Evaluation. In the Eleventh International Conference on Digital Society and eGovernment. Nice, France, $19-23$ March 2017. IARIA: USA

Karakaya-Ozyer, K. and Aksu-Dunya, B., 2018. A review of structural equation modelling applications in Turkish educational science literature. International Journal of Research in Education and Science, 4(1), pp. 279-291

Kyem, P.A.K., 2016. Mobile Phone Expansion and Opportunities for E-Governance in sub-Saharan Africa. The Electronic Journal of Information Systems in Developing Countries, 75(6), pp. 1-15.

Manenji, T. and Marufu, B., 2016. The impact of adopting e-government as a mechanism to enhance accountability as well as transparent conduct within public institutions. Scholedge International Journal of Business Policy and Governance, 3(7), pp.84-101.

Mawela, T., Ochara, N.M. and Twinomurinzi, H., 2016. E-Government Implementation: A Reflection on South African Municipalities. South African Computer Journal, 29(1), pp. 147-171.

Mellouli, M., Bentahar, O. and Bidan, M., 2016. Trust and e-government acceptance: The case of Tunisian on-line tax filing. The Electronic Journal Information Systems Evaluation, 19(3), pp. 197-212.

Mudzana, T. and Maharaj, M., 2017. Toward an Understanding of Business Intelligence Systems Success: A South African Study. The Electronic Journal Information Systems Evaluation, 20(1), pp. 24-38.

Munyoka, W. and Maharaj, M.S., 2019. Privacy, security, trust, risk and optimism bias in e-government use: The case of two Southern African Development Community countries. SA Journal of Information Management, 21(1), pp. 1-9.

Munyoka, W. and Maharaj. M., 2017a. Understanding eGovernment Utilisation within the SADC, IST-Africa 2017 Conference Proceedings, Windhoek, Namibia, 31 May-2 June 2017. IEEE

Munyoka, W., and Maharaj. M. 2017b. The effect of UTAUT2 moderator factors on citizens' intention to adopt egovernment: the case of two SADC countries. Problems and Perspectives in Management, 15(1), pp. 115-123. 
Munyoka, W. and Manzira, M.F., 2013. Alignment of e-Government Policy Formulation with Practical Implementation: The Case of Sub-Saharan. International Journal of Social, Behavioural, Educational, Economic, Business and Industrial Engineering, 7(12), pp. 3034-3039.

Mutula, S.M. and Olasina, G., 2014. E-government strategies in Sub-Saharan Africa: Failures and successes. In Digital Access and E-Government: Perspectives from Developing and Emerging Countries (pp. 297-312). IGI Global.

Nkohkwo, Q.N. and Islam, M.S., 2013. Challenges to the Successful Implementation of e-Government Initiatives in SubSaharan Africa: A Literature Review. Electronic Journal of e-Government, 11(2), pp. 253-253.

Organisation for Economic Co-operation and Development (OECD), 2013. Principles on Digital Government Strategies: Bringing Governments Closer to Citizens and Businesses. (GOV/PGC/EGOV, 2013). Bern: OECD.

Otieno, I. and Omwenga, E., 2016. Citizen-Centric Critical Success Factors for the Implementation of E-Government: A Case Study of Kenya Huduma Centres. Journal of Emerging Trends in Computing and Information Sciences, 7(2), pp. 102109.

Qasem, M., and Zolait, A.U. 2016. Determinants of Behavioural Intentions towards Using E-Government Services in the Kingdom of Bahrain. International Journal of Computing and Digital Systems, 5(4), pp. 345-355.

Palvia, S.C.J. and Sharma, S.S., 2007. E-government and e-governance: definitions/domain framework and status around the world. In $5^{\text {th }}$ International Conference on E-governance. Foundations of E-Government, Hyderabad, India, 28-30 December 2007. ACM New York: USA.

Rajah, N., 2015. E-Government in Zimbabwe: An Overview of Progress Made and Challenges Ahead. Journal of Global Research in Computer Science, 6(12), pp. 11-16.

Rana, N.P., Dwivedi, Y.K. and Williams, M.D., 2013. Evaluating Alternative Theoretical Models for Examining Citizen Centric Adoption of E-Government. Transforming Government: People, Process and Policy. 7(1), pp. 27-49.

Ruhode, E., 2016. E-Government for Development: A Thematic Analysis of Zimbabwe's Information and Communication Technology Policy Documents. The Electronic Journal of Information Systems in Developing Countries, 73(7), pp. 1-15.

Sá, F., Rocha, Á. and Cota, M.P., 2016. From the quality of traditional services to the quality of local e-government online services: A literature review. Government Information Quarterly, 33(1), pp. 149-160.

Salganik, M.J., 2006. Variance estimation, design effects, and sample size calculations for respondent-driven sampling. Journal of Urban Health, 83(1), pp.98-112.

Samuel, O., 2014. Human factor issues in the use of e-government services among Ghanaian middle age population: Improving usability of existing and future government virtual interactive systems design. Journal of Information Engineering and Applications, 4(4), pp. 85-106

Schuppan. T., 2009. E-Government in developing countries: Experiences from sub-Saharan Africa. Government Information Quarterly, 26, pp. 118-127.

Sekaran, U. and Bougie, R., 2016. Research Methods for Business: A Skill Building Approach. ${ }^{\text {th }}$ Ed. New Jersey: John Wiley and Sons.

Sharma, S.K., 2015. Adoption of e-government services: The role of service quality dimensions and demographic variables. Transforming Government: People, Process and Policy, 9(2), pp.207-222.

United Nations. 2018. E-Government Survey 2018, gearing e-government to support transformation towards sustainable and resilient societies, New York, USA

Venkatesh, V., Thong, J.Y.L., Chan, F.K.Y. and Hu, P.J.H., 2016. Managing Citizens' Uncertainty in E-Government Services: The Mediating and Moderating Roles of Transparency and Trust. Information Systems Research, 27(1), pp. 87-111.

Venkatesh, V., Thong, J.Y.L. and Xu, X., 2012. Consumer Acceptance and Use of Information Technology: Extending the Unified Theory of Acceptance and Use of Technology. MIS Quarterly, 36(1), pp. 157-178.

Venkatesh, V., Morris, M.G., Davis, G.B. and Davis, F.D., 2003. User acceptance of information technology: toward a unified view. MIS Quarterly, 27(3), pp. 425-478.

Verkijika, S.F. and De Wet, L., 2018. E-Government Development in Sub-Saharan Africa. Electronic Commerce Research and Applications, 30, pp. 83-93.

Yonazi, J., Sol, H. and Albert Boonstra, A., 2010. Exploring Issues Underlying Citizen Adoption of eGovernment Initiatives in Developing Countries: The Case of Tanzania. Electronic Journal of e-Government, 8(2), pp. 176-188. 